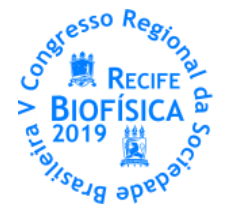

\title{
THE LIPID BILAYER COMPOSITION INFLUENCES ON INTERACTION OF POLYANIONS WITH ALPHA-HEMOLYSIN CHANNEL
}

\author{
Luciana R. Teixeira ${ }^{1 *}$, Antonio A. B. Neto², Gabriela S. P. Lima², Dijanah C. Machado ${ }^{1}$, Cláudio G. Rodrigues ${ }^{1}$ \\ ${ }^{1}$ Laboratório de Biofísica das Membranas e Células-Tronco - Dr. Oleg Krasilnikov, Departamento de Biofísica e Radiobiologia, UFPE \\ ${ }^{2}$ Curso de Medicina, UNINASSAU \\ *lucianarateixeira@gmail.com
}

\section{INTRODUCTION}

Staphylococcus aureus is a gram-positive bacterium of the Micrococcaceae family. It is the main human pathogen causing several types of clinical infections from a simple infection, such as boils, to most severe diseases as endocarditis, bacteremia, sepsis and toxic shock syndrome (LOWY, 1998; SANTOS et al., 2007; OTTO, 2014; COHEN et al., 2016). This bacterium produces various exotoxins, such as alpha hemolysin $(\mathrm{aHL})$, that collaborate to its capacity to colonize mammalian hosts and to cause several diseases (DINGES et al., 2000).

The alpha hemolysin $(\mathrm{aHL})$ is a water soluble $33 \mathrm{kD}$ protein toxin (BHAKDI \& TRANUM-JENSEN, 1991; MELO et al., 2016) that has the ability to incorporate into the cell membrane and, then, to form an ion channel. Besides that, the aHL is involved in inflammasome activation and induction of pro-inflammatory cytokines secretion implicated in tissue necrosis and inflammation processes (CRAVEN et al., 2009).

The aHL represents one of the virulence factors of Staphylococcus aureus, thus to use a drug that blocks the action of this toxin is a way to inhibit the staphylococcus infection progression (SANTOS et al., 2007; TONG et al., 2015). The great concern worldwide is the high incidence of hospital infection and resistance to antibiotics, mainly to the beta lactam class, presented by strains of this bacterium (TONG et al., 2015; COHEN et al., 2016). Therefore, is important to look for new compounds that inhibit the Staphylococcus aureus toxins, particularly $\mathrm{a}-\mathrm{HL}$, as well as the understanding of the mechanisms involved in the inhibition (QIU et al., 2013; RANI et al., 2014).

Over the years, studies have reported protective properties of polyanions against bacterial infections (REMINGTON \& MERIGAN, 1970; ZARETZKY et al., 1995; GUO et al., 2017). Our group demonstrated that polyanion heparin blocks ion channels formed by $\mathrm{aHL}$ in a concentration and molecular weight-dependent manner. (TEIXEIRA et al., 2009). In presence of $\mathrm{Ca}^{+2}$, the heparin binds to phosphate groups of the phospholipids by divalent cation bridges (HUSTER AND ARNOLD, 1998; MERZLYAK et al., 1999). Such interaction increases polyanion concentration close to membrane surface that, in turn, increases the probability of polyanion enter into a channel and blocks it (SINN et al., 2006; TEIXEIRA et al., 2009). It is believed that the length and degree of unsaturation of the hydrocarbon chains of phospholipids may modify the local environment and orientation of the phosphate groups (ROLLAND et al., 1996; MESHKOV et al., 1998) responsible for interaction with ions and other charged molecules. With this in mind, in this study we decided to investigate the influence of lipid composition of planar lipid bilayers on the effectiveness of heparin to block aHL channels. The results are discussed in terms of the influence of bilayer composition on interaction $\mathrm{Ca}^{+2} /$ heparin and the repercussion of this on aHL channel blockade.

\section{MATERIALS AND METHODS}

The wild type of Staphylococcus aureus alpha-hemolysin was purchased from Calbiochem (Madison, WI). The cholesterol (Chol) and all phospholipids: 1,2-diphytanoyl-sn-glycero-3phosphatidylcholine (DPhPC), phosphatidylcholine (PC), phosphatidylserine (PS), phosphatidylinositol (PI), phosphatidylethanolamine (PE) were purchased from Avanti Polar Lipids (Alabaster, AL). Heparin $6000 \mathrm{~g} / \mathrm{mol}$ (H-5284, Hep6000), $\mathrm{CaCl}_{2}$, EDTA, 2-amino-2-hydroxymethyl-1,3-propanediol (TRIS), and $\mathrm{HCl}$ were purchased from Sigma (St. Louis, MO). All reagents were used as received. Milli-Q plus water (Millipore, Bedford, MA) with resistivity of $18 \mathrm{M} \Omega \mathrm{cm}$ was used to prepare all aqueous buffer. The bath solution was composed of $50 \mathrm{mM} \mathrm{CaCl}$, $1 \mathrm{mM}$ EDTA, $10 \mathrm{mM}$ TRIS- $\mathrm{HCl}$, at $\mathrm{pH} 7.5$.

For single channel experiments, the bilayer lipid membranes were formed from DPhPC by solvent-free method (MONTAL; MUELLER, 1972). After membrane formation, an aliquot of aHL stock solution $(0.07 \mathrm{mg} / \mathrm{ml})$ was added to one side of the experimental chamber (defined as Cis throughout this study) to promote the incorporation of a single channel.

Multichannel experiments were carried out at planar lipid bilayers formed by the painting technique (MUELLER et al., 1963) from $\mathrm{PC} /$ Chol; PE/Chol; PS/Chol; PI/Chol mixture (ratio 2:1, M/M). After membrane formation, an amount of aHL stock was added to $C$ is side to promote the incorporation of multiple channels.

From multichannels experiments, to evaluate the action of the Hep6000 on the channel, it was calculated the characteristic time constant of the current decay $(\tau)$. The current "relaxation" was fitted by a single exponential function:

$$
I(t)=I_{0} \exp \left(\frac{-t}{\tau}\right)+I_{S S}
$$

where, $I_{0}$ is the ionic current amplitude in reply to the voltage pulse applied at multichannel bilayer; $t$ is the time of the process; $\boldsymbol{\tau}$ is the characteristic time and $I_{s s}$ is the steady-state current value.

All experiments were done using an Axopatch 200A amplifier (Axon Instruments, Foster (ity, CA) in voltage clamp mode. Membrane potential was maintained using $\mathrm{Ag} / \mathrm{AgCl}$ electrodes in $3 \mathrm{M} \mathrm{KCl} 2 \%$ agarose bridges assembled within standard $200 \mu \mathrm{L}$ pipette tips. Currents were filtered by a low-pass eight-pole Bessel filter (Model 9002, Frequency Devices, Haverhill, MA), digitized with a sampling frequency of $0.5 \mathrm{kHz}$ (for multichannel experiments) or $50 \mathrm{kHz}$ (for single channel recording), stored on a computer and analyzed by 
electrophysiology software developed by Dr. M. A. Pustovoit (Petersburg Nuclear Physics Institute, Gatchina, Russia). For data analysis was used statistical software Origin 9.0. Data are reported as the mean \pm SD obtained in 3-7 independent experiments.

\section{RESULTS AND DISCUSSION}

The single channel conductance incorporated in different lipid bilayer membranes $(G)$ in symmetrical solutions was defined as

$$
\mathrm{G}=\frac{\mathrm{I}}{\mathrm{V}}
$$

where $I$ is the transmembrane current flowing through the channels and $\mathbf{V}$ corresponds to the applied potential. Both ionic current recording and probability histogram of aHL channel are shown in Figure 1. The histograms usually have a well-defined peak that was fitted with a Gaussian curve. The value of the most probable channel conductance was established to be of $\sim 120 \mathrm{pS}$. Only the channels with a conductance close to this nominal value were used to study the heparin effects at a single $\alpha \mathrm{HL}$ channel.

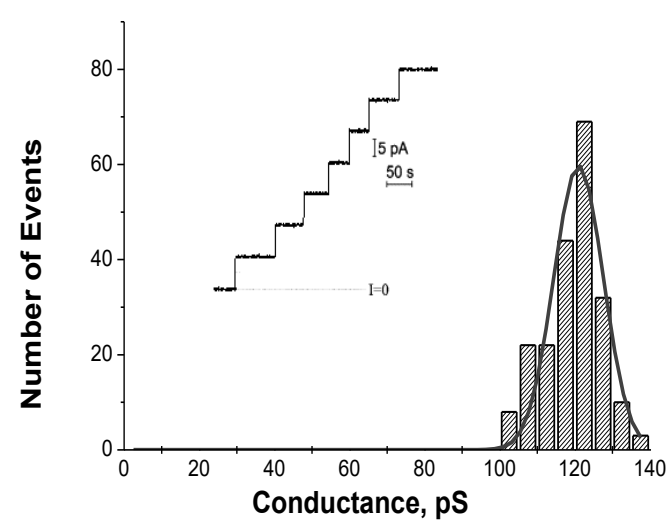

Figure 1. Conductance histogram of single channels formed by aHL. The inset illustrates a typical current recording of single channels spontaneously formed by $\mathrm{aHL}$, which was added to the cis compartment (final concentration $\sim 5 \mathrm{ng} / \mathrm{ml}$ ). The histogram is comprised of the conductance values of 200 channels (5-15 channels per membrane) and the bin width is 6 pS. The solid line indicates the best fit of a single normal distribution to the most probable conductance values near $\sim 120 \mathrm{pS}$. The applied potential was $40 \mathrm{mV}$. Planar lipid bilayer membranes were formed from DPhPC. Bath solution was composed of $50 \mathrm{mM} \mathrm{CaCl}, 1 \mathrm{mM}$ EDTA, $10 \mathrm{mM}$ TRIS-HCl, at pH 7.5. All other conditions for the experiment are described in the Materials and Methods section.

Initially, to test the Heparin blocking effect, in multichannel experiments the transmembrane voltage was increased stepwise from 0 to $100 \mathrm{mV}$. Ionic current traces of the $\mathrm{aHL}$ in the absence and presence of heparin, at $100 \mathrm{mV}$ applied potential, can be seen in Figure 2. In the absence of heparin, the current traces remained constant. However, the presence of Hep6000 caused relatively rapid current reduction. The current relaxations were well described by a single exponential function.

In addition, to evaluate the influence of bilayer lipid composition on effectiveness of heparin in blocking the $\mathrm{aHL}$ channel, we performed multichannels experiments with bilayer membrane formed by phospholipids from different polar heads: phosphatidylcholine (PC), phosphatidylserine (PS), phosphatidylinositol (PI), phosphatidylethanolamine (PE).

It was observed an influence of the type of lipid in membrane compositions on the $\mathrm{aHL}$ ion channel sensitivity to Hep6000 (Figure $3)$.

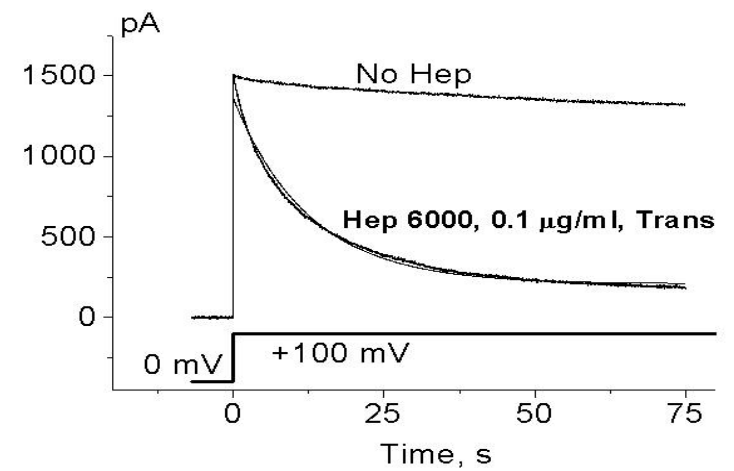

Figure 2. Representations current traces. Control traces (no Hep6000), the macroscopic current remains unaltered (single line). The current decays after application of $100 \mathrm{mV}$ to multichannel bilayers in the presence of Hep6000 at the Trans compartment of the experimental chamber (double line). Best-fit of a single exponential function. All other conditions for the experiment are described in Materials and Methods.

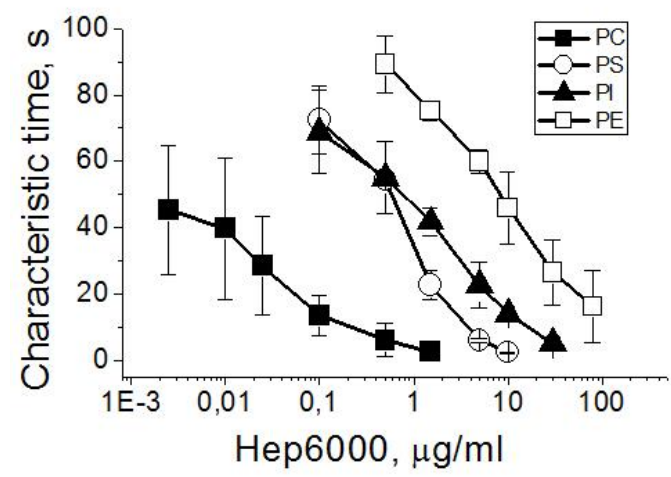

Figure 3. Influence of the lipid composition on heparin/aHL interaction. Heparin effects on aHL channels inserted in lipid bilayers of different composition. Hep6000 was added in the Trans. Applied potential was $100 \mathrm{mV}$. All other conditions for the experiment are described in Materials and Methods.

It is known that PC and PE both are neutral but amphoteric; and PI and PS, both have one negative charge per molecule (MCLAUGHLIN et al., 1971). The preliminary results analysis had demonstrated that the influence of composition of the lipid bilayer on the sensitivity of the aHL channel to Heparin 6000 is ranked as follows:

$$
\mathrm{PC} \gg \mathrm{PS} \approx \mathrm{PI}>\mathrm{PE}
$$

The results demonstrate that the reduction of the characteristic time constant values under effect of the Hep6000 was bigger in channels incorporated in bilayers formed by neutral phospholipid phosphatidylcholine (PC).

In this study, it was used bath solution contained $\mathrm{Ca}^{+2}$ ions, divalent cations interact with phosphate groups of phospholipids and introduce a positive charge at the membrane surface (PAPAHADJOPOULOS, 1968; ALSOP et al., 2016). This action can provide $\mathrm{Ca}^{+2}$ bridge formation between phosphate groups of phospholipids in the membranes and the sulfate groups on the polyanions molecules (ARNOLD et al., 1990) as well as an increase in concentration of negatively charged polyanions at membrane-solution interfaces. In turn, this negatively charged polyanions concentration-increase should increase the probability of the channel block by polyanions. Our results indicate that PC membranes bind to $\mathrm{Ca}^{2+}$ ions with high affinity, which determines a significant electrostatic attraction with Hep6000 and consequently a more effective channel blocking effect. For the other neutral phospholipid, phosphatidylethanolamine (PE), the effectiveness of the Hep6000 in blocking the aHL channel was eight-fold lower than PC membrane. This indicates that addition of divalent cations did not produce detectable surface potential, i.e., little or no $\mathrm{Ca}^{+2}$ binding occurs to the polar head of PE phospholipid. 
The influence of the phospholipids charge used in our studies demonstrated that the effectiveness of Hep6000 on the channel $\mathrm{aHL}$ decreased when these channels were incorporated in lipid bilayers constituted by phospholipids which present negatively charge polar heads, such as phosphatidylserine (PS) and phosphatidylinositol (PI). In comparison to lipid bilayer formed by PC, the channels were less sensitive to the action of Hep6000 on membranes composed of PS and PI. As $\mathrm{Ca}^{2+}$-phospholipids interaction is a result of electrostatic interaction between the phosphate group of phospholipids with $\mathrm{Ca}^{+2}$ ions, which is directly related to the exposure of the phosphate, the charged polar head of phospholipids can decrease the exposure their phosphate groups, and therefore reducing $\mathrm{Ca}^{+2}$ binding.

These findings indicate that the interaction of $\mathrm{Ca}^{2+}$ with lipid membranes depends on the exposure and density of phosphate groups in phospholipids at membrane surface. Thus, we demonstrate that the polar head group of phospholipids in the membranes affects their interaction with divalent ions by changing their surface potential, and therefore influences the effectiveness of heparin in blocking $\mathrm{aHL}$ channels.

\section{CONCLUSIONS}

Here, we show that the type of polar head of phospholipids influences indirectly the exposure of the phosphate groups and consequently the effectiveness of Hep6000 in blocking aHL channels. The interaction of $\mathrm{Ca}^{+2}$ ions with phosphate groups determines the $\mathrm{Ca}^{+2}$ binding to lipid membranes, which promotes an electrostatic attraction of the Hep6000 (negatively charged) to the solution-membrane interface. It was established that phosphatidylcholine (PC) membranes bind to $\mathrm{Ca}^{+2}$ ions with high affinity. These results can be of interest for pharmacology area.

\section{REFERENCES}

ALSOP, R. J.; SCHOBER, R. M.; RHEINSTÄDTER, M. C. Swelling of phospholipid membranes by divalent metal ions depends on the location of the ions in the bilayers. Soft Matter, v. 12, p. 6737-6748, 2016.

ARNOLD, K.; OKHI, S.; KRUMBIEGEL, M. Interaction of dextran sulfate with phospholipid surfaces and liposome aggregation and fusion. Chemistry and physics of lipids, v. 55, p. 301-307, 1990.

BHAKDI, S.; TRANUM-JENSEN, J. Alpha-toxin of Staphylococcus aureus. Microbiological Research, v. 55, p. 733-751, 1991.

COHEN, T. S. et al. Staphylococcus aureus a toxin potentiates opportunistic bacterial lung infections. Science translational medicine, v. 8, p. 1-11, 2016.

CRAVEN, R. R. et al. Staphylococcus aureus a-hemolysin activates the NLRP3-inflammasome in human and mouse monocytic cells. PloS one, v. 4, p. 1-11, 2009.

DINGES, M. M.; ORWIN, P. M. SCHLIEVERT, P. M. Exotoxins of Staphylococcus aureus. Clinical Microbiology Reviews, Washington, v. 13, p. 16-34, 2000.

GUO, J. et al. Polyanionic antimicrobial membranes: an experimental and theoretical study. Langmuir, 33(17), 4346-4355. 2017.

HUSTER, D.; ARNOUD. K. Ca ${ }^{2+}$-mediated interaction between dextran sulfate and dimyristoyl-sn-glycero-3-phosphocholine surfaces studied by $\mathrm{H}-2$ nuclear magnetic resonance. Biophysical Journal, v. 75, p. 909-916, 1998.

LOWY, F. D. Staphylococcus aureus infections. New England journal of medicine, v. 339, p. 520-532, 1998.

MCLAUGHLIN, S. G.; SZABO. G.; FISENMAM. G. Divalent lons and Surface Potential of Charged Phospholipid Membranes. Journal of General Physiology, v. 58, p.667-687,1971.

MELO, M. C. et al. Inhibition of the hemolytic activity caused by Staphylococcus aureus alpha-hemolysin through isatin-Schiff copper (II) complexes. FEMS microbiology letters, v. 363, p. 1-5, 2016.
MERZLYAK, P. G. et al. Polymeric nonelectrolytes to probe pore geometry: application to the a-toxin transmembrane channel. Biophysical Journal, v. 77, p. 3023-3033, 1999.

MESHKOV, B. B.; TSYBYHEV, V. P.; LIVSHITS, V. A. The interaction of double-charged metal ions with monolayers and bilayers of phospholipids. Russian Chemical Bulletin, v. 47, p. 2410-2414. 1998.

MONTAL, M.; MUELLER. P. Formation of Bimolecular Membranes from Lipid Monolayers and A Study of Their Electrical Properties. Proceedings of the National Academy of Sciences of the United States of America, v. 69, p. 3561-3566. 1972.

MUELLER, P. et al. Methods for the formation of single bimolecular lipid membranes in aqueous solution. The journal of physical chemistry, v. 67, p. 534-535, 1963.

OTTO, M. Staphylococcus aureus toxins. Current opinion in microbiology, v. 17, p. 32-37. 2014.

PAPAHADJOPOULOS, D. Surface properties of acidic phospholipids: interaction of monolayers and hydrated liquid crystals with uni-and bi-valent metal ions. Biochimica et Biophysica Acta (BBA)Biomembranes, v. 163, p. 240-254, 1968.

QIU, J. et al. Molecular modeling reveals the novel inhibition mechanism and binding mode of three natural compounds to Staphylococcal alpha-hemolysisn. PLOS One, v. 8, p. 80197, 2013.

RANI, N. et al. Inhibition of pore formation by blocking the assembly of Staphylococcus aureus alpha hemolysin through a novel peptide inhibitor: an in silico approach. International Journal of Peptide Research and Therapeutics, v. 20, p. 575-583, 2014.

REMINGTON, J. S.; MERIGAN, T. C. Synthetic polyanions protect mice against intracellular bacterial infection. Nature, v. 226, p. 361, 1970.

ROLLAND, J. P.; SANTAELLA, C.; VIERLING, P. Molecular packing of highly fluorinated phosphatidylcholines in monolayers. Chemistry and Physics of Lipids, v. 79, p.71-77, 1996.

SANTOS, A. L. et al. Staphylococcus aureus: visiting a strain of clinical importance. Jornal Brasileiro de Patologia e Medicina Laboratorial, v. 43, p. 413-423. 2007.

SINN, C. G.; ANTONIETTI, M.; DIMOVA, R. Binding of calcium to phosphatidylcholine-phosphatidylserine membranes. Colloids and Surfaces A-Physicochemical and Engineering Aspects, v. 282, p.410-419, 2006.

TEIXEIRA, L. R. et al., Interaction of Heparins and Dextran Sulfates with a Mesoscopic Protein Nanopore. Biophysical Journal, v. 97, p. 2894-2903, 2009.

TONG, S. Y. C. et al, Staphylococcus aureus infections: epidemiology, pathophysiology, clinical manifestations, and management. Clinical microbiology reviews, v. 28, p. 603-661, 2015.

ZARETZKY, F. R.; PEARCE-PRATT, R.; PHILLIPS, D. M. Sulfated polyanions block Chlamydia trachomatis infection of cervix-derived human epithelia. Infection and immunity, v. 63, p. 3520-3526, 1995.

ZITZER, A. O.; BHAKDI, S.; PALME, M. Oligomerization of Vibrio cholerae cytolysin yields a pentameric pore and has a dual specificity for cholesterol and sphingolipids in the target membrane. The Journal of Biological Chemistry, v. 274, p. 1375-1380, 1999. 